\title{
Pyoderma Gangrenosum and Interleukin Inhibitors: A Semi-Systematic Review
}

\author{
Hakim Ben Abdallah Karsten Fogh Christian Vestergaard Rikke Bech \\ Department of Dermatology, Aarhus University Hospital, Aarhus, Denmark
}

\begin{abstract}
Keywords
Pyoderma gangrenosum · Anakinra - Ustekinumab ·

Canakinumab $\cdot$ Interleukin inhibitors
\end{abstract}

\begin{abstract}
Background: Pyoderma gangrenosum (PG) is a rare ulcerating skin disease associated with multiple comorbidities and increased mortality. In recent decades, newer biologics such as interleukin inhibitors have been used to treat PG; however, the literature is scarce, consisting predominantly of case reports and caseseries. The aim of our review was to evaluate the effectiveness and safety of interleukin inhibitors for the treatment of PG in adults. Summary: A literature search was conducted using search terms related to PG and interleukin inhibitors in databases such as PubMed, Embase, Scopus, Web of Science, and Cochrane Library. The study eligibility criteria included patients diagnosed with PG, over the age of 18 , and treated with an interleukin inhibitor. Our study included 60 papers describing 81 patients fulfilling the eligibility criteria. The treatment with interleukin inhibitors resulted in $70 \%(95 \% \mathrm{Cl} 59-80 \%)$ response and $57 \%(95 \% \mathrm{Cl}$ 45-68\%) complete response rates, and few (4\%) mild adverse events, hence supporting the off-label use for the treatment of recalcitrant PG in adults. The response and complete response rates were 59\% (17/29) and 38\% (11/29) for anakinra, 64\% (7/11) and 55\% (6/11) for canakinumab, and $79 \%$ (27/34) and 71\% (24/34) for ustekinumab, respectively. Limitations include publication bias that might have
\end{abstract}

karger@karger.com

(c) 2021 S. Karger AG, Basel

www.karger.com/drm

Karger" overestimated the efficacy as successful cases responding to treatment are more likely to be reported than nonresponding cases. Additionally, the heterogeneity of the treatment groups does not allow conclusions of superiority or inferiority of the different interleukin inhibitors to be drawn. Further studies are needed to investigate the efficacy of the different interleukin inhibitors and to investigate the importance of underlying disease for treatment response.

(c) 2021 S. Karger AG, Basel

\section{Introduction}

Pyoderma gangrenosum (PG) is a rare immune-mediated ulcerative skin disease. PG is often associated with prior trauma or underlying disease $[1,2]$. Neutrophils play a key role in the pathogenesis of PG and accumulate in the dermis. The immune dysregulation in PG has not yet been fully understood, but it involves $\mathrm{T}$ cells, neutrophils, and inflammatory mediators. Proinflammatory cytokines such as TNFa, interleukin-1 (IL-1), IL-6, IL-8, IL17, and IL-23 are upregulated in the skin with PG [3-9]. The management of PG relies mainly upon immunosuppression with no acknowledged treatment guidelines, but systemic corticosteroids and oral cyclosporine are frequently used drugs [10]. In recent decades, biologics in the form of TNFa inhibitors have been used, and a recent

ORCID number Hakim Ben Abdallah: 0000-0002-4610-5428.
Correspondence to:

Hakim Ben Abdallah, hba@ clin.au.dk 
semi-systematic review has demonstrated the effectiveness of TNFa inhibitors in the treatment of PG [11]. However, the effectiveness of newer biologics such as interleukin inhibitors remains unknown. Therefore, the aim of this paper was to review the therapeutic effectiveness and safety of interleukin inhibitors in adults with PG.

\section{Methods}

Our review has been reported in accordance with the Preferred Reporting Items for Systematic Reviews and Meta-Analyses (PRISMA) statement [12]. However, all items were not applicable, thus the classification as a semi-systematic review, because the data were individual-level rather than group-level due to a paucity of larger studies. This review uses a similar approach to the study selection and data extraction as the semi-systematic review for TNFa inhibitors [11].

\section{Search Strategy}

The literature search included publications from 1998 to 2021 and was conducted in the following databases: PubMed, Embase, Scopus, Web of Science, and Cochrane Library. Moreover, literature was searched in World Health Organization International Clinical Trials Registry Platform, Trials Register of Promoting Health Interventions, The National Technical Information Service, NICE Local Practice Case Studies, Open Grey, NHS Evidence, and UK Clinical Trials Gateway. The search terms were related to PG and interleukin inhibitors and truncated to retrieve results with all word endings. There were no language restrictions (see online suppl. Table 1 for the full search strategy; for all online suppl. material, see www.karger.com/doi/10.1159/000519320). Additionally, citations were manually searched through the reference list of publications included in our review.

\section{Study Selection}

All publications identified through database searching were merged and duplicates were removed. Subsequently, a screening process based on examination of titles and abstracts led to relevant publications that were full-text assessed for inclusion. Inclusion criteria for studies and case reports were (1) patients diagnosed with PG, (2) over the age of 18, and (3) administered an interleukin inhibitor with the therapeutic response reported. Publications were excluded (1) if patients had been reported in a prior publication to prevent duplicates or (2) if PG occurred during interleukin inhibitor treatment because an assessment of treatment response was not possible.

\section{Data Extraction}

For each patient, the following data items were extracted: age, sex, number and location of PG lesions, duration and type of PG, comorbidities, previous and concomitant treatment, interleukin inhibitor agent, treatment response, time to response and complete healing, reoccurrence of PG after complete healing, and adverse events.

The primary endpoint was treatment response and defined as either complete response (complete healing of PG lesions or major improvement within weeks without follow-up reported), partial response (significant improvement of lesions and symptoms), or no response (minimal improvement, no change, or worsening of lesions and symptoms). Treatment response was assessed based on the findings reported in the publications. Moreover, the assessment of treatment response was based on all lesions rather than a single target lesion.

The outcome measures were response (percentage of patients with partial or complete response) and complete response rates (percentage of patients with complete response).

Patients administered multiple courses or different interleukin inhibitors were reported based on the initial treatment attempt in order to have interleukin inhibitor-naive patients and reduce concomitant medication.

\section{Statistical Analyses}

Fisher's exact test was used to compare categorical data, whereas one-way ANOVA was used to compare means. Missing data were excluded from the analyses. $p$ values $<0.05$ were considered statistically significant. The analyses were performed with the SAS 9.4 software.

\section{Results}

The literature search identified 1,151 unique publications (online suppl. Fig. 1 with flow diagram of the selection process). The screening based on examination of titles and abstracts excluded 789 citations, leaving 362 publications that underwent full-text assessment (online suppl. Table 2 with excluded publications with reasons of exclusion), resulting in the inclusion of 60 publications describing 81 patients (online suppl. Tables 3 and 4) [3, $5,13-70]$.

\section{Demographic and Clinical Characteristics}

The mean age of the included 81 patients was 43.34 years, with a sex distribution of $49 \%$ females and $51 \%$ males (Table 1). The number of PG lesions was multiple $(>1)$ in $68 \%$ of patients, and the lower limbs were the site of predilection (49\%). A total of $22 \%$ of cases were not associated with underlying disease (idiopathic). The prevalence of idiopathic PG was significantly lower $(p=0.0115)$ among patients treated with anakinra (7\%) compared to patients treated with canakinumab $(45 \%)$ or ustekinum$\mathrm{ab}(28 \%)$, whereas the prevalence of hidradenitis suppurativa or autoinflammatory syndromes was statistically significantly $(p<0.0001)$ higher among patients treated with either anakinra (59\%) or canakinumab (45\%) than among patients treated with ustekinumab (3\%). The prevalence of inflammatory bowel disease was significantly higher $(p=0.0029)$ among patients treated with ustekinumab (50\%) compared to patients treated with anakinra (14\%) or canakinumab (9\%). Overall, 18 and $6 \%$ 
Table 1. Demographic and clinical characteristics of the included patients $(n=81)$ by overall and treatment group (anakinra, canakinumab, ustekinumab)

\begin{tabular}{|c|c|c|c|c|c|}
\hline Characteristics & All & Anakinra & Canakinumab & Ustekinumab & $p$ value \\
\hline \multicolumn{6}{|l|}{ Age } \\
\hline Mean $\pm S D$, years & $43.34 \pm 14.99$ & $39.24 \pm 15.27$ & $42.64 \pm 18.94$ & $46.41 \pm 12.45$ & 0.1899 \\
\hline Missing values & 5 & 0 & 0 & 5 & \\
\hline \multicolumn{6}{|l|}{ Sex } \\
\hline Female & $49 \%(36 / 73)$ & $35 \%(9 / 26)$ & $36 \%(4 / 11)$ & $62 \%(18 / 29)$ & \\
\hline Male & $51 \%(37 / 73)$ & $65 \%(18 / 26)$ & $64 \%(7 / 11)$ & $38 \%(11 / 29)$ & 0.1005 \\
\hline Missing values & 8 & 3 & 0 & 5 & \\
\hline \multicolumn{6}{|l|}{ Location of PG } \\
\hline Lower limb(s) & $49 \%(31 / 63)$ & $27 \%(6 / 22)$ & $64 \%(7 / 11)$ & $61 \%(14 / 23)$ & \\
\hline Torso & $16 \%(10 / 63)$ & $18 \%(4 / 22)$ & $27 \%(3 / 11)$ & $13 \%(3 / 23)$ & \\
\hline Other body parts ${ }^{\mathrm{a}}$ & $13 \%(8 / 63)$ & $23 \%(5 / 22)$ & $0 \%(0 / 11)$ & $4 \%(1 / 23)$ & \\
\hline Multiple body parts ${ }^{b}$ & $22 \%(14 / 63)$ & $32 \%(7 / 22)$ & $9 \%(1 / 11)$ & $22 \%(5 / 23)$ & 0.1094 \\
\hline Missing values & 18 & 7 & 0 & 11 & \\
\hline \multicolumn{6}{|l|}{ Number of PG lesions } \\
\hline Single & $32 \%(20 / 63)$ & $32 \%(7 / 22)$ & $27 \%(3 / 11)$ & $30 \%(7 / 23)$ & \\
\hline Multiple (>1) & $68 \%(43 / 63)$ & $68 \%(15 / 22)$ & $73 \%(8 / 11)$ & $70 \%(16 / 23)$ & 1.0000 \\
\hline Missing values & 18 & 7 & 0 & 11 & \\
\hline \multicolumn{6}{|l|}{ Associated diseases } \\
\hline $\mathrm{IBD}$ & $21 \%(21 / 79)$ & $14 \%(4 / 29)$ & $9 \%(1 / 11)$ & $50 \%(16 / 32)$ & 0.0029 \\
\hline Hematologic diseases & $6 \%(5 / 79)$ & $7 \%(2 / 29)$ & $0 \%(0 / 11)$ & $6 \%(2 / 32)$ & 1.0000 \\
\hline HS or autoinflammatory disorders ${ }^{c}$ & $32 \%(25 / 79)$ & $59 \%(17 / 29)$ & $45 \%(5 / 11)$ & $3 \%(1 / 32)$ & $<0.0001$ \\
\hline Rheumatic diseases & $18 \%(14 / 79)$ & $14 \%(4 / / 29)$ & $0 \%(0 / 11)$ & $19 \%(6 / 32)$ & 0.3895 \\
\hline No associated diseases & $22 \%(17 / 79)$ & $7 \%(2 / 29)$ & $45 \%(5 / 11)$ & $28 \%(9 / 32)$ & 0.0115 \\
\hline Missing values & 2 & 0 & 0 & 2 & \\
\hline \multicolumn{6}{|l|}{ Duration of PG } \\
\hline$<12$ weeks & $14 \%(7 / 49)$ & $0 \%(0 / 12)$ & $10 \%(1 / 10)$ & $15 \%(3 / 20)$ & \\
\hline$>12$ weeks & $86 \%(42 / 49)$ & $100 \%(12 / 12)$ & $90 \%(9 / 10)$ & $85 \%(17 / 20)$ & 0.4441 \\
\hline Missing values & 32 & 17 & 1 & 14 & \\
\hline \multicolumn{6}{|l|}{ Previous treatment } \\
\hline Yes & $100 \%(79)$ & $100 \%(29)$ & $100 \%(11)$ & $100 \%(32)$ & \\
\hline No & $0 \%(0)$ & $0 \%(0)$ & $0 \%(0)$ & $0 \%(0)$ & \\
\hline Missing values & 2 & 0 & 0 & 2 & \\
\hline \multicolumn{6}{|l|}{ Previous TNFa inhibitor treatment } \\
\hline Yes & $63 \%(50 / 79)$ & $62 \%(18 / 29)$ & $45 \%(5 / 11)$ & $75 \%(24 / 32)$ & \\
\hline No & $37 \%(29 / 79)$ & $38 \%(11 / 29)$ & $55 \%(6 / 11)$ & $25 \%(8 / 32)$ & 0.2053 \\
\hline Missing values & 2 & 0 & 0 & 2 & \\
\hline
\end{tabular}

Data are presented as \% $(n)$ of patients, unless otherwise specified. Missing values were excluded from the statistical analyses. HS, hidradenitis suppurativa; IBD, inflammatory bowel disease; PG, pyoderma gangrenosum; SD, standard deviation. ${ }^{a}$ Body parts including upper limb(s), anogenital region, and head region. ${ }^{b}$ PG located at least on two of the following body parts: upper limb(s), lower limb(s), torso, anogenital area, extracutaneous area, or head region. ' Including PAPA, PAMI, PASH, PAPASH, PASS, and PAC syndromes.

of PG cases were associated with rheumatologic and hematologic diseases, respectively, but no significant differences were observed between the groups of patients treated with anakinra, canakinumab, or ustekinumab. The duration of PG lesions was more $>12$ weeks in $86 \%$ of patients. Before treatment with interleukin inhibitors, all patients had tried another treatment: $97,5 \%$ of patients had tried systemic treatment, mainly immunosuppressives in the form of corticosteroid steroids, cyclosporine, methotrexate, or biologics, and $63 \%$ of patients had tried TNFa inhibitors.

\section{Treatment and Response}

A total of 34 patients were treated with ustekinumab (anti-IL-12/23), 29 patients with anakinra (IL-1 receptor antagonist), and 11 patients with canakinumab (anti-IL$1 \beta$ ) (Table 2). Moreover, 3 patients were treated with secukinumab (anti-IL-17A), whereas 2 patients were 
Table 2. Response and complete response rates to interleukin inhibitors with subgroup analyses based on interleukin inhibitor agent, associated disease, and duration of PG $(n=81)$

\begin{tabular}{|c|c|c|c|c|}
\hline & Response rate & Complete response rate & $p$ value $^{\mathrm{a}}$ & $p$ value $^{b}$ \\
\hline No stratification & $\begin{array}{l}70 \%(57 / 81) \\
(95 \% \text { Cl 59-80\%) }\end{array}$ & $\begin{array}{l}57 \%(46 / 81) \\
(95 \% \mathrm{Cl} 45-68 \%)\end{array}$ & & \\
\hline \multicolumn{5}{|l|}{ Interleukin inhibitor } \\
\hline Anakinra & $59 \%(17 / 29)$ & $38 \%(11 / 29)$ & 0.1269 & 0.0185 \\
\hline Canakinumab & $64 \%(7 / 11)$ & $55 \%(6 / 11)$ & 0.7241 & 1.0000 \\
\hline Ustekinumab & $79 \%(27 / 34)$ & $71 \%(24 / 34)$ & 0.1473 & 0.0420 \\
\hline Missing values & 0 & 0 & & \\
\hline \multicolumn{5}{|l|}{ Associated disease } \\
\hline $\mathrm{IBD}$ & $67 \%(14 / 21)$ & $62 \%(13 / 21)$ & 0.7850 & 0.6188 \\
\hline Hematologic diseases & $60 \%(3 / 5)$ & $60 \%(3 / 5)$ & 0.6368 & 1.0000 \\
\hline HS or autoinflammatory disease $\mathrm{e}^{c}$ & $56 \%(14 / 25)$ & $36 \%(9 / 25)$ & 0.1133 & 0.0146 \\
\hline Rheumatic disease & $64 \%(9 / 14)$ & $57 \%(8 / 14)$ & 0.7502 & 1.0000 \\
\hline No associated diseases & $94 \%(16 / 17)$ & $76 \%(13 / 17)$ & 0.0158 & 0.0971 \\
\hline Missing values & 2 & 2 & & \\
\hline \multicolumn{5}{|l|}{ Duration of PG } \\
\hline$<12$ weeks & $86 \%(6 / 7)$ & $71 \%(5 / 7)$ & & \\
\hline$>12$ weeks & $79 \%(33 / 42)$ & $60 \%(25 / 42)$ & 1.0000 & 0.6909 \\
\hline Missing values & 32 & 32 & & \\
\hline
\end{tabular}

Data are presented as \% ( $n$ ) of patients, unless otherwise specified. Missing values were excluded from the statistical analyses. HS, hidradenitis suppurativa; IBD, inflammatory bowel disease; PG, pyoderma gangrenosum. ${ }^{a}$ Calculated by Fisher's exact test for response rates (the percentage of patients with partial or complete response).

${ }^{b}$ Calculated by Fisher's exact test for complete response rates (the percentage of patients with complete response).

' Including PAPA, PAMI, PASH, PAPASH, PASS, and PAC syndromes.

treated with brodalumab (anti-IL-17 receptor), 1 patient with tocilizumab (anti-IL-6 receptor), and 1 patient with tildrakizumab (anti-IL-23). Overall, the response and complete response rates to interleukin inhibitors were $70 \%$ (95\% CI 59-80\%) and 57\% (95\% CI 45-68\%), respectively.

The complete response rate for anakinra (38\%) was significantly lower $(p=0.0185)$ compared to the other interleukin inhibitors, while that for ustekinumab (71\%) was significantly higher $(p=0.0420)$.

Patients without associated diseases showed higher complete response rates and statistically significantly higher response rates than patients with associated comorbidity $(p=0.0158)$. Patients with hidradenitis suppurativa or autoinflammatory syndrome showed less favorable response $(56 \%, p=0.1133)$ and complete response $(36 \%, p=0.0146)$ compared to other patients without hidradenitis suppurativa or autoinflammatory syndrome. No other statistically significant differences were found in the subgroup analyses of comorbidities or duration of PG. No severe adverse events were reported (Table 3), but $4 \%$ (3/78) reported mild adverse events (painful nodules at injection sites, erysipelas, or arthralgia).
Table 3. Additional clinical characteristics

\begin{tabular}{ll}
\hline Clinical characteristics & \\
\hline Adverse effects & $4 \%(3 / 78)$ \\
Missing values & 3 \\
\hline Reoccurrence of PG & $7 \%(3 / 45)$ \\
Missing values & 1 \\
\hline Mean time (SD) and & $24.32(21.54)$, \\
range to complete healing, weeks & $3-104$ (range) \\
Missing values & 12 \\
\hline
\end{tabular}

PG, pyoderma gangrenosum; SD, standard deviation.

\section{Discussion}

\section{Findings}

The treatment with interleukin inhibitors provided 70\% (95\% CI 59-80\%) response and 57\% (95\% CI 45$68 \%$ ) complete response rates and few (4\%) mild adverse events, thus supporting the off-label use for the treatment of PG. The therapeutic response is high when considering 
that the study population represented recalcitrant PG as indicated by the fact that all patients had tried another treatment, $63 \%$ had tried TNFa inhibitors, and $86 \%$ had PG lesions for $>12$ weeks before treatment with interleukin inhibitors.

The response and complete response rates to interleukin inhibitors in our study were marginally lower but broadly similar to those found for TNFa inhibitors [11], cyclosporine, and systemic corticosteroid [10]. Recently, a semi-systematic review $(n=356)$ with the same methodology as this review found an 87\% (95\% CI 93-90\%) response and an 67\% (95\% CI 62-72\%) complete response rate to TNFa inhibitors. Moreover, approximately $90 \%$ response and $47 \%$ complete response rates to cyclosporine or oral corticosteroid were found in a randomized controlled trial $(n=112)$. However, when comparing these rates to those of interleukin inhibitors, it is important to take into consideration that the patients treated with interleukin inhibitors are recalcitrant cases.

In our review, the complete response rates of $71 \%$ to ustekinumab and of $38 \%$ to anakinra were, respectively, statistically significantly higher $(p=0.0420)$ and lower ( $p=0.0185)$ compared to those of other interleukin inhibitors. A similar trend was found in a cohort study with $66 \%(6 / 9)$ response and 44\% (4/9) complete response rates to ustekinumab and $0 \%(0 / 4)$ response and complete rates to anakinra [71], although, based on the low number of patients, these findings show that the effect of anakinra was inferior to that of other interleukin inhibitors. However, this should be interpreted cautiously due to differences in both known (e.g., associated diseases) and unknown factors (e.g., ulcer size) among the treatment groups. In our review, the associated diseases were not evenly distributed among the treatment groups (Table 2) and might have biased the results. Both anakinra and canakinumab exert their effect through IL-1 inhibition. Anakinra is an IL-1 receptor antagonist, while canakinumab is a humanized monoclonal antibody targeting IL-1 $\beta$. Canakinumab showed a nonsignificant difference to the other interleukin inhibitors, suggesting that IL-1 inhibition, and thus theoretically anakinra, is effective to treat PG. However, the different mode of action between anakinra and canakinumab may reflect clinical differences. A systematic review found that $64 \%$ (9/14) achieved complete response to canakinumab among 14 patients with familial Mediterranean fever who had insufficient response to anakinra [72], though another systematic review $(n=104)$ found no significant difference in treatment response of anakinra and canakinumab in patients with familial Mediterranean fever [73]. Neverthe-

Pyoderma Gangrenosum and Interleukin Inhibitors less, future trials with PG are needed before conclusions can be drawn about differences in effectiveness among the different interleukin inhibitors.

Our study suggests that inhibition of IL-1 (anakinra and canakinumab) and IL-12/23 (ustekinumab) may be effective therapeutic options in refractory PG in adults.

In our review, 4 patients treated with either tildrakizumab, tocilzumab, or brodalumab achieved complete response (4/4). Three patients were treated with secukinumab; 1 achieved no response, 1 achieved complete response, and 1 achieved partial response. Due to the small sample size, further studies are needed to evaluate the therapeutic options on inhibition of IL-6 (tocilizumab), IL-17 (secukinumab and brodalumab), and IL23 (tildrakizumab).

Although most likely underreported due to inconsistent reporting of the included papers and too short follow-up, only 4\% (4/78) experienced mild adverse events, suggesting that interleukin inhibitors may be safe to use in PG.

\section{Limitations}

Due to the data originating from case reports and series, publication bias might have overestimated efficacy. Likewise, concomitant therapies might have overestimated efficacy. Limitations with the outcome measure instruments include risk of misclassification due to variable follow-up time and lack of uniform and objective assessment of lesions. Given the challenge of diagnosis, patients might have been misdiagnosed with PG in the papers included in our review. Another limitation was that the data were incomplete due to missing values.

Due to the observational nature of the included studies, the treatment groups are incomparable because of uneven distribution of both known (e.g., underlying disease) and unknown potential confounding variables; thus, conclusions of the comparison of the different interleukin inhibitors cannot be drawn due to the heterogeneity of the treatment groups.

\section{Conclusion}

Our study suggests that inhibition of IL-1 (anakinra and canakinumab) and IL-12/23 (ustekinumab) may be effective and safe therapeutic options in moderate to severe recalcitrant PG in adults. Further studies are warranted to compare the efficacy of the different interleukin inhibitors with other biologic agents, cyclosporine and corticosteroid, and to investigate the importance of un- 
derlying disease to treatment response from different medical therapies. Also, international consensus on diagnostic, severity, and outcome measure instruments would provide better evidence for PG.

\section{Key Message}

Our study suggests that inhibition of IL-1 (anakinra and canakinumab) and IL-12/23 (ustekinumab) may be effective and safe therapeutic options in moderate to severe recalcitrant PG in adults.

\section{Conflict of Interest Statement}

The authors have no conflict of interest to declare.

\section{Funding Sources}

The authors received no specific funding for this work.

\section{Author Contributions}

H. Ben Abdallah, K. Fogh, and R. Bech made substantial contributions to the conception and design of the study. H. Ben Abdallah drafted the manuscript. K. Fogh, C. Vestergaard, and R. Bech revised it critically of important intellectual content. All authors made substantial contributions to the interpretation of data, approved the final version to be published, and agreed to be accountable for all aspects of the work.

\section{Data Availability Statement}

All data generated or analyzed during this study are available in the article or online supplementary material. Further enquiries can be directed to the corresponding author.

\section{References}

1 Kridin K, Cohen AD, Amber KT. Underlying systemic diseases in pyoderma gangrenosum: a systematic review and meta-analysis. Am J Clin Dermatol. 2018 Aug;19(4):479-87.

2 Maverakis E, Marzano AV, Le ST, Callen JP, Brüggen $\mathrm{MC}$, Guenova E, et al. Pyoderma gangrenosum. Nat Rev Dis Primers. 2020 Oct; 6(1):81.

3 Guenova E, Teske A, Fehrenbacher B, Hoerber S, Adamczyk A, Schaller M, et al. Interleukin 23 expression in pyoderma gangrenosum and targeted therapy with ustekinumab. Arch Dermatol. 2011 Oct;147(10):1203-5.

4 Marzano AV, Fanoni D, Antiga E, Quaglino P, Caproni M, Crosti C, et al. Expression of cytokines, chemokines and other effector molecules in two prototypic autoinflammatory skin diseases, pyoderma gangrenosum and Sweet's syndrome. Clin Exp Immunol. 2014 Oct;178(1):48-56.

5 Lee WS, Choi YJ, Yoo WH. Use of tocilizum$\mathrm{ab}$ in a patient with pyoderma gangrenosum and rheumatoid arthritis. J Eur Acad Dermatol Venereol. 2017 Feb;31(2):e75-7.

6 Marzano AV, Damiani G, Ceccherini I, Berti E, Gattorno M, Cugno M. Autoinflammation in pyoderma gangrenosum and its syndromic form (pyoderma gangrenosum, acne and suppurative hidradenitis). Br J Dermatol. 2017 Jun;176(6):1588-98.

7 Ahn C, Negus D, Huang W. Pyoderma gangrenosum: a review of pathogenesis and treatment. Expert Rev Clin Immunol. 2018 Mar 14(3):225-33.

8 Marzano AV, Borghi A, Wallach D, Cugno M. A comprehensive review of neutrophilic diseases. Clin Rev Allergy Immunol. 2018 Feb;54(1):114-30.
9 Marzano AV, Ortega-Loayza AG, Heath M, Morse D, Genovese G, Cugno M. Mechanisms of inflammation in neutrophil-mediated skin diseases. Front Immunol. 2019;10: 1059.

10 Ormerod AD, Thomas KS, Craig FE, Mitchell E, Greenlaw N, Norrie J, et al. Comparison of the two most commonly used treatments for pyoderma gangrenosum: results of the STOP GAP randomised controlled trial. BMJ. 2015 Jun;350:h2958.

11 Ben Abdallah H, Fogh K, Bech R. Pyoderma gangrenosum and tumour necrosis factor alpha inhibitors: a semi-systematic review. Int Wound J. 2019 Apr;16(2):511-21.

12 Moher D, Liberati A, Tetzlaff J, Altman DG Preferred Reporting Items for Systematic Reviews and Meta-Analyses: the PRISMA statement. BMJ. 2009 Jul;339(7):b2535

13 Brenner M, Ruzicka T, Plewig G, Thomas P, Herzer P. Targeted treatment of pyoderma gangrenosum in PAPA (pyogenic arthritis, pyoderma gangrenosum and acne) syndrome with the recombinant human interleukin-1 receptor antagonist anakinra. Br J Dermatol. 2009 Nov;161(5):1199-201.

14 Hsiao JL, Antaya RJ, Berger T, Maurer T, Shinkai K, Leslie KS. Hidradenitis suppurativa and concomitant pyoderma gangrenosum: a case series and literature review. Arch Dermatol. 2010 Nov;146(11):1265-70.

15 McAleer MA, Murphy M, Bourke J. Rituximab therapy for resistant erosive lichen planus and pyoderma gangrenosum. Br J Dermatol. 2010;163(2):445.

16 Bennett M, McAleer MA, Murphy M, Harney S, Bourke JF. Novel combination of intravenous immunoglobulin and rituximab in the treatment of recalcitrant pyoderma gangrenosum. Br J Dermatol. 2011;165:35.

17 Lin Z, Hegarty JP, Lin T, Ostrov B, Wang Y, $\mathrm{Yu} \mathrm{W}$, et al. Failure of anakinra treatment of pyoderma gangrenosum in an IBD patient and relevance to the PSTPIP1 gene. Inflamm Bowel Dis. 2011 Jun;17(6):E41-2.

18 Braun-Falco M, Kovnerystyy O, Lohse P, Ruzicka T. Pyoderma gangrenosum, acne, and suppurative hidradenitis (PASH) - a new autoinflammatory syndrome distinct from PAPA syndrome. J Am Acad Dermatol. 2012 Mar;66(3):409-15.

19 Demidowich AP, Freeman AF, Kuhns DB, Aksentijevich I, Gallin JI, Turner ML, et al. Brief report: genotype, phenotype, and clinical course in five patients with PAPA syndrome (pyogenic sterile arthritis, pyoderma gangrenosum, and acne). Arthritis Rheum. 2012 Jun;64(6):2022-7.

20 Fahmy M, Ramamoorthy S, Hata T, Sandborn WJ. Ustekinumab for peristomal pyoderma gangrenosum. Am J Gastroenterol. 2012 May; 107(5):794-5.

21 Goldminz AM, Botto NC, Gottlieb AB. Severely recalcitrant pyoderma gangrenosum successfully treated with ustekinumab. J Am Acad Dermatol. 2012 Nov;67(5):e237-8.

22 Geusau A, Mothes-Luksch N, Nahavandi H, Pickl WF, Wise CA, Pourpak Z, et al. Identification of a homozygous PSTPIP1 mutation in a patient with a PAPA-like syndrome responding to canakinumab treatment. JAMA Dermatol. 2013 Feb;149(2):209-15.

23 Hoffmann P, Ombrello AK, Stone DL, Barron KS, Kastner DL. PW03-017 - combination TNF and IL-1 blockade in PAPA syndrome. Pediatr Rheumatol. 2013;11(Suppl 1):A243. 
24 Jaeger T, Andres C, Grosber M, Zirbs M, Hein $\mathrm{R}$, Ring J, et al. Pyoderma gangrenosum and concomitant hidradenitis suppurativa - rapid response to canakinumab (anti-IL-1beta). Eur J Dermatol. 2013 May-Jun;23(3):408-10.

25 Yoo L, Elwir S, Tinsley A, Williams E. A case report of a patient with Crohn's disease complicated by pyoderma gangrenosum treated with intravenous immunoglobulin. Am J Gastroenterol. 2013;108:S421.

26 Acquitter M, Plantin P, Kupfer I, Auvinet H, Marhadour T. Anakinra improves pyoderma gangrenosum in psoriatic arthritis: a case report. Ann Intern Med. 2015 Jul;163(1):70-1.

27 Kolios AG, Maul JT, Meier B, Kerl K, TraidlHoffmann C, Hertl M, et al. Canakinumab in adults with steroid-refractory pyoderma gangrenosum. Br J Dermatol. 2015 Nov; 173(5): 1216-23.

28 McAllister BP, Williams ED, Yoo LJ, Tinsley A, Koltun W, Ardell CM, et al. Refractory peristomal pyoderma gangrenosum successfully treated with intravenous immunoglobulin: a case report. Am J Gastroenterol. 2015; 110(12):1739-40.

29 Meyersburg D. Multilocular superficial pyoderma gangrenosum or PAPA syndrome successful treatment with ustekinumab. Aktuelle Dermatol. 2015;41(7):300-3.

30 Staub J, Pfannschmidt N, Strohal R, BraunFalco M, Lohse P, Goerdt S, et al. Successful treatment of PASH syndrome with infliximab, cyclosporine and dapsone. J Eur Acad Dermatol Venereol. 2015 Nov;29(11):22437.

31 Vahlquist A, Håkansson LD, Rönnblom L, Karawajczyk M, Fasth A, van Gijn ME, et al. Recurrent pyoderma gangrenosum and cystic acne associated with leucocyte adhesion deficiency due to novel mutations in ITGB2: successful treatment with infliximab and adalimumab. Acta Derm Venereol. 2015 Mar;95(3): 349-51.

32 Zeeli T, Padalon-Brauch G, Ellenbogen E, Gat A, Sarig O, Sprecher E. Pyoderma gangrenosum, acne and ulcerative colitis in a patient with a novel mutation in the PSTPIP1 gene. Clin Exp Dermatol. 2015 Jun;40(4):367-72.

33 Barbosa NS, Tolkachjov SN, El-Azhary RA, Davis MD, Camilleri MJ, McEvoy MT, et al. Clinical features, causes, treatments, and outcomes of peristomal pyoderma gangrenosum (PPG) in 44 patients: the Mayo Clinic experience, 1996 through 2013. J Am Acad Dermatol. 2016;75(5):931-9.

34 Cosgarea I, Lovric Z, Körber A, Dissemond J. Successful treatment of refractory pyoderma gangrenosum with ustekinumab only after excision of renal cell carcinoma. Int Wound J. 2016 Oct;13(5):1041-2.

35 Faleri S, Feichtner K, Ruzicka T. Severe acne in autoinflammatory diseases. Hautarzt. 2016 Nov;67(11):897-901. German.

36 Galimberti RL, Vacas AS, Bollea Garlatti ML, Torre AC. The role of interleukin- $1 \beta$ in pyoderma gangrenosum. JAAD Case Rep. 2016 Sep;2(5):366-8.
37 Greb JE, Gottlieb AB, Goldminz AM. Highdose ustekinumab for the treatment of severe, recalcitrant pyoderma gangrenosum. Dermatol Ther. 2016 Nov;29(6):482-3.

38 Leuenberger M, Berner J, Di Lucca J, Fischer L, Kaparos N, Conrad C, et al. PASS syndrome: an IL-1-driven autoinflammatory disease. Dermatology. 2016;232(2):254-8.

39 Omenetti A, Carta S, Caorsi R, Finetti M, Marotto D, Lattanzi B, et al. Disease activity accounts for long-term efficacy of IL-1 blockers in pyogenic sterile arthritis pyoderma gangrenosum and severe acne syndrome. Rheumatology (Oxford). 2016 Jul;55(7):1325-35.

40 Benzaquen M, Monnier J, Beaussault Y, Rouby $\mathrm{F}$, Berbis $\mathrm{P}$. Pyoderma gangrenosum arising during treatment of psoriasis with adalimumab: effectiveness of ustekinumab. Australas J Dermatol. 2017 Nov;58(4):e270-1.

41 Beynon C, Chin MF, Hunasehally P, Bhagwandas K, Bevan M, Taylor M, et al. Successful treatment of autoimmune disease-associated pyoderma gangrenosum with the IL-1 receptor antagonist anakinra: a case series of 3 patients. J Clin Rheumatol. 2017 Apr;23(3): 181-3.

42 Heard LK, Richardson VN, Lewis CM, Davis LS. A case of autoinflammatory skin and bone disease flared by a change in osteoporosis management. JAAD Case Rep. 2017 Mar; 3(2):103-5.

43 Jennings L, Molloy O, Quinlan C, Kelly G, O'Kane M. Treatment of pyoderma gangrenosum, acne, suppurative hidradenitis (PASH) with weight-based anakinra dosing in a hepatitis B carrier. Int J Dermatol. 2017 Jun;56(6):e128-9.

44 Pinard J, Chiang DY, Mostaghimi A, Granter SR, Merola JF, Barkoudah E. Wounds that would not heal: pyoderma gangrenosum. Am J Med. 2018 Apr;131(4):377-9.

45 Sun NZ, Ro T, Jolly P, Sayed CJ. Non-response to interleukin-1 antagonist canakinumab in two patients with refractory pyoderma gangrenosum and hidradenitis suppurativa. J Clin Aesthet Dermatol. 2017 Sep;10(9):36-8.

46 De Risi-Pugliese T, Seksik P, Bouaziz JD, Chasset F, Moguelet P, Gornet JM, et al. Ustekinumab treatment for neutrophilic dermatoses associated with Crohn's disease: a multicenter retrospective study. J Am Acad Dermatol. 2019 Mar;80(3):781-4.

47 Fleisher M, Marsal J, Lee SD, Frado LE, Parian A, Korelitz BI, et al. Effects of vedolizumab therapy on extraintestinal manifestations in inflammatory bowel disease. Dig Dis Sci. 2018;63(4):825-33.

48 Gargallo V, Menis D, Delgado Márquez AM, Aróstegui JI, Llamas Martín R. Short-term efficacy of adalimumab in a patient with pyrinassociated autoinflammation with neutrophilic dermatosis. J Dtsch Dermatol Ges. 2018;16(6):756-9.

49 Haebich G, May K, Patel GK. Ustekinumab treatment of ulcerative colitis-associated pyoderma gangrenosum in a patient with adalim- umab-induced renal failure. Br J Dermatol. 2018;179:154.

50 Joseph N, Hostoffer R, Tcheurekdjian H. A novel gene mutation associated with common variable immunodeficiency and pyoderma. Ann Allergy Asthma Immunol. 2018;121(5): S94.

51 Klötgen HW, Beltraminelli H, Yawalkar N, van Gijn ME, Holzinger D, Borradori L. The expanding spectrum of clinical phenotypes associated with PSTPIP1 mutations: from PAPA to PAMI syndrome and beyond. Br J Dermatol. 2018;178(4):982-3.

52 Low ZM, Mar A. Treatment of severe recalcitrant pyoderma gangrenosum with ustekinumab. Australas J Dermatol. 2018 May;59(2):131-4.

53 Nasifoglu S, Heinrich B, Welzel J. Successful therapy for pyoderma gangrenosum with a Janus kinase 2 inhibitor. Br J Dermatol. 2018; 179(2):504-5.

$54 \mathrm{Ng} \mathrm{A}$, Aamer M, Warburton KL, Montgomery R, Laws P. Use of anakinra in treatmentresistant pyoderma gangrenosum. Br J Dermatol. 2018;179:71-2.

55 Nguyen Y, Lowe P. A complex case of vulval pyoderma gangrenosum. Australas J Dermatol. 2018;59:4-5.

56 Nieto D, Sendagorta E, Rueda JM, Herranz P. Successful treatment with ustekinumab and vacuum-assisted closure therapy in recalcitrant myelodysplastic syndrome-associated pyoderma gangrenosum: case report and literature review. Clin Exp Dermatol. 2019 Jan; 44(1):116-9.

57 Sonbol H, Duchatelet S, Miskinyte S, Bonsang B, Hovnanian A, Misery L. PASH syndrome (pyoderma gangrenosum, acne and hidradenitis suppurativa): a disease with genetic heterogeneity. Br J Dermatol. 2018;178(1):e17-8.

58 Kochar B, Herfarth N, Mamie C, Navarini AA, Scharl M, Herfarth HH. Tofacitinib for the treatment of pyoderma gangrenosum. Clin Gastroenterol Hepatol. 2019;17(5):9913.

59 Moreno Garcia M, Madrid Gonzalez M, Prada Lobato JM. Secukinumab for pyoderma gangrenosum: a case report. Med Clin (Barc). 2019 Mar;152(6):246.

60 Nunes G, Patita M, Fernandes V. Refractory pyoderma gangrenosum in a patient with Crohn's disease: complete response to ustekinumab. J Crohns Colitis. 2019 May; 13(6):812-3.

61 Piqueras-Garcia J, Sahuquillo-Torralba AJ, Torres-Navarro I, Botella-Estrada R. Pyoderma gangrenosum with ulcerative colitis successfully treated with ustekinumab. Actas Dermosifiliogr (Engl Ed). 2019 Nov;110(9): 776-8.

62 Sadik CD, Thieme M, Zillikens D, Terheyden P. First emergence of pyoderma gangraenosum, palmoplantar pustulosis and sacroiliitis in a psoriasis patient associated with switching from secukinumab to brodalumab. J Eur Acad Dermatol Venereol. 2019 Nov;33(11): e406-7. 
63 Vallerand IA, Hardin J. Ustekinumab for the treatment of recalcitrant pyoderma gangrenosum: a case report. SAGE Open Med Case Rep. 2019 May;7:2050313x19845206.

64 Gawdzik A, Ponikowska M, Jankowska-Konsur A, Woźniak Z, Maj J, Szepietowski JC. Paradoxical skin reaction to certolizumab, an overlap of pyoderma gangrenosum and psoriasis in a young woman treated for ankylosing spondylitis: case report with literature review. Dermatol Ther (Heidelb). 2020 Aug; 10(4):869-79.

65 John JM, Sinclair RD. Tildrakizumab for treatment of refractory pyoderma gangrenosum of the penis and polymyalgia rheumatica: killing two birds with one stone. Australas J Dermatol. 2020 May;61(2):170-1.
66 McPhie ML, Kirchhof MG. Pyoderma gangrenosum treated with secukinumab: a case report. SAGE Open Med Case Rep. 2020 Jul; 8:2050313x20940430.

67 Oymanns M, Kreuter A, Assaf C. Anakinra therapy in a patient with multifocal pyoderma gangrenosum and hidradenitis suppurativa. Hautarzt. 2021 May;72(5):435-8. German.

68 Petty AJ, Whitley MJ, Balaban A, Ellington K, Marano AL. Pyoderma gangrenosum induced by secukinumab in a patient with psoriasis successfully treated with ustekinumab. JAAD Case Rep. 2020 Aug;6(8):731-3.

69 Phillips FM, Verstockt B, Sebastian S, Ribaldone D, Vavricka S, Katsanos K, et al. Inflammatory cutaneous lesions in inflammatory bowel disease treated with vedolizumab or ustekinumab: an ECCO CONFER multicentre case series. J Crohns Colitis. 2020 Oct; 14(10):1488-93.
70 Tee MW, Avarbock AB, Ungar J, Frew JW. Rapid resolution of pyoderma gangrenosum with brodalumab therapy. JAAD Case Rep. 2020 Nov;6(11):1167-9.

71 Herberger K, Dissemond J, Brüggestrat S, Sorbe C, Augustin M. Biologics and immunoglobulins in the treatment of pyoderma gangrenosum - analysis of 52 patients. J Dtsch Dermatol Ges. 2019 Jan;17(1):32-41.

72 Kacar M, Savic S, van der Hilst JCH. The efficacy, safety and tolerability of canakinumab in the treatment of familial Mediterranean fever: a systematic review of the literature. J Inflamm Res. 2020;13:141-9.

73 van der Hilst JC, Moutschen M, Messiaen PE, Lauwerys BR, Vanderschueren S. Efficacy of anti-IL-1 treatment in familial Mediterranean fever: a systematic review of the literature. Biologics. 2016;10:75-80. 